\title{
Conversion of PP, HDPE and LDPE Plastics Into Liquid Fuels and Chemical Precursors by Thermal Cracking
}

\section{Yuliana Rodriguez Lamar}

USFQ: Universidad San Francisco de Quito

\section{José Noboa}

USFQ: Universidad San Francisco de Quito

Andrés S. Torres Miranda

USFQ: Universidad San Francisco de Quito

Daniela Almeida Streitwieser ( $\nabla$ dalmeida@usfq.edu.ec)

USFQ: Universidad San Francisco de Quito https://orcid.org/0000-0001-7024-421X

\section{Research Article}

Keywords: Plastic waste valorization, polypropylene, high density polyethylene, low density polyethylene, thermal cracking, kinetic study

Posted Date: February 19th, 2021

DOI: https://doi.org/10.21203/rs.3.rs-211010/v1

License: (9) This work is licensed under a Creative Commons Attribution 4.0 International License. Read Full License 


\section{Conversion of PP, HDPE and LDPE plastics into}

\section{liquid fuels and chemical precursors by thermal}

\section{cracking}

Yuliana Rodríguez Lamar ${ }^{\dagger}$, José Noboa ${ }^{\ddagger}$, Andrés S. Torres Miranda ${ }^{\ddagger}$, Daniela Almeida Streitwieser ${ }^{\dagger} *$

$\dagger$ Institute for Development of Alternative Energies and Materials IDEMA, Department of Chemical Engineering, Universidad San Francisco de Quito USFQ, EC 170901 Quito, Ecuador

\section{ABSTRACT}

The inappropriate disposal of plastic waste cause serious environmental problems. Nowadays, alternative processes are being studied for the sustainable reutilization of plastics. One of these options is the cracking into shorter liquid hydrocarbon fractions, while maintaining its basic chemical structure. The energetic potential from the original plastics structure remains and the fractions can be used as fuels and chemical precursors. This research addresses the kinetic study of thermal cracking of polypropylene (PP) and high- and low-density polyethylene (HDPE and LDPE) in a batch reactor. The kinetics of the reaction can be described as a firstorder rate with the lowest activation energy using PP, followed by HDPE and LDPE with values of $367.28 \mathrm{~kJ} / \mathrm{mol}, 453.37 \mathrm{~kJ} / \mathrm{mol}$ and $457.96 \mathrm{~kJ} / \mathrm{mol}$, respectively. The yield obtained for the liquid fraction is highest for LDPE, with a value of $72 \%$ at $390^{\circ} \mathrm{C}$, followed by HDPE and LDPE with $69 \%$ and $62 \%$ at $375^{\circ} \mathrm{C}$. The liquid fractions obtained from the process were 
characterized according to ASTM standards, obtaining that LDPE and HDPE fractions have similar properties to diesel, while PP is closer to gasoline. The fractions were also analyzed by means of gas chromatography identifying the main products of the reaction and establishing a possible reaction mechanism.

KEYWORDS: Plastic waste valorization, polypropylene, high density polyethylene, low density polyethylene, thermal cracking, kinetic study.

\section{INTRODUCTION}

Plastic products have multiple applications and they have become essential elements in modern life, but their short life cycle and inappropriate disposal are causing serious environmental, social and economic problems [1]. In the last decades, the production of disposable polymers and the resulting solid waste generation has increased dramatically. In 1950, global plastic production was 2 million tons, since then, annual production has increased almost 200 times, reaching 360 million tons in 2018 [2]. This value is equivalent to approximately two-thirds of the world's population [3]. In 2018, the plastics with highest production were polypropylene (PP), low-density polyethylene (LDPE) and high-density polyethylene (HDPE) with 10, 9 and 6 million tons, respectively $[4,5]$.

This situation causes an uprising environmental concern due to the lack of efficient methods for plastic waste disposal. Among the produced plastic, only $9 \%$ is recycled, $12 \%$ is incinerated and $79 \%$ is released into oceans and landfills [6]. The main difficulty with recycling, meaning the recasting of plastic into new products, is the intensive work required to classify the type of polymer and their transparency and color [7]. Also, some plastics cannot be recycled due to their structure and the amount of additives contained. In most of the cases the additives are 
toxic, and they may hinder the separation of the main polymer and harm the quality of the new plastic products [8]. Another important method for plastic disposal is incineration, which is a thermal process that generates energy from plastic waste using steam turbines. Even if this process is the most widely used nowadays [9], it generates acid gases, carcinogenic dioxins and it releases heavy metals, causing problems in the ecosystem and people's health [10]. Also in this case only its high heating value can be exploited, while its chemical structure is being destroyed [11].

As observed, recycling and incineration technologies are insufficient to manage the total production of plastic waste. According to statistics, by 2025 there will be 250 million tons of plastic in the oceans and landfills [12]. The plastic waste present in the marine environment not only affects fauna and flora, it also endangers people's health by threatening the security of human food chain [13]. Therefore, a circular economy of plastics has been encouraged, where the responsibility of the producer extends to the post-consumption stage of the product's useful life; namely, the producer controls the environmental impact of his product, preventing plastics from ending up as waste [14]. Although incineration of plastic waste has increased [14], the aim is to use plastic waste as a secondary resource. Therefore, more sustainable and reliable methods for the revalorization of plastic residue must be developed [15]. Some research has focused on recovering the energetic potential of plastics, for example by thermal or catalytic cracking reactions, taking advantage of the high heat capacity containing in their structure [16$18]$.

Thermal cracking is the breakdown of long chains of polymer molecules into smaller and less complex units through heat and pressure [19]. Plastic residues are classified as secondary raw materials with great potential for thermal or catalytic cracking due to the long chain hydrocarbons in their structure. In addition, unlike biomass, plastics do not contain oxygen, so higher carbon efficiency is expected [20]. Thermal cracking can produce $80 \mathrm{wt} \%$ of a liquid 
hydrocarbon and this yield can be optimized by varying the parameters of the cracking process $[21,22]$. Operating conditions, such as temperature, pressure, residence time, heating rates, feedstock composition and presence of moisture or toxic elements have the highest impact on the reaction rate and they influence the composition of the gaseous, liquid and waste fractions produced during cracking [23]. These parameters can be varied depending on the desired product. For example, more gas fractions are obtained with temperatures over $500^{\circ} \mathrm{C}$, while between $300^{\circ} \mathrm{C}$ and $500^{\circ} \mathrm{C}$, a higher amount of liquid hydrocarbons are obtained [22].

In this work, liquid hydrocarbon products from the thermal cracking of PP, HDPE and LDPE are investigated using a laboratory batch reactor. The experimental data was used to perform a kinetic study and a comparison of the thermal reaction performance between the different plastic pellets. The products obtained from the cracking reaction were characterized according to ASTM standards for liquid fuels, as well as gas chromatography. Additionally, a possible reaction mechanism was presented to understand the decomposition of each polymer and its products.

\section{EXPERIMENTAL METHODS}

Sample Collection. The plastic pellets used in the study for the thermal cracking were primary plastic pellets of polypropylene (PP, type 412MK49) from SABIC, high-density polyethylene (HDPE, type HS5502) from Braskem and low-density polyethylene (LDPE, type 2601) from Dow Chemical Company. The reason for using primary pellets in this investigation is to define the kinetic parameters for the thermal cracking reaction without the effect of plastic aging or contaminants.

Experimental Setup. The equipment used for the thermal cracking of plastics was a Precision Scientific Petroleum Herzog distiller with a maximum power of $1100 \mathrm{~W}$. A detail description 
of the setup can be found at Vargas et al [24]. For each experiment, $40 \mathrm{~g}$ of plastic pellets (i.e. PP, HDPE and LDPE) were placed into the reactor. At the start, the power was set to 550W for 5 minutes and then increased steadily with a ramp of 55W every 5 minutes until the desired power was reached. The reaction time of thermal cracking was 150 minutes, once the desired temperature was constant. Three experimental conditions were used for the PP plastics: $770 \mathrm{~W} / 360^{\circ} \mathrm{C}, 825 \mathrm{~W} / 370^{\circ} \mathrm{C}, 858 \mathrm{~W} / 375^{\circ} \mathrm{C}$, while four temperatures were studied for HDPE and LDPE: $858 \mathrm{~W} / 375^{\circ} \mathrm{C}, 880 \mathrm{~W} / 380^{\circ} \mathrm{C}, 935 \mathrm{~W} / 390^{\circ} \mathrm{C}, 990 \mathrm{~W} / 400^{\circ} \mathrm{C}$.

Figure 1 shows the relationship between the power of the batch reactor and the reactor temperature.

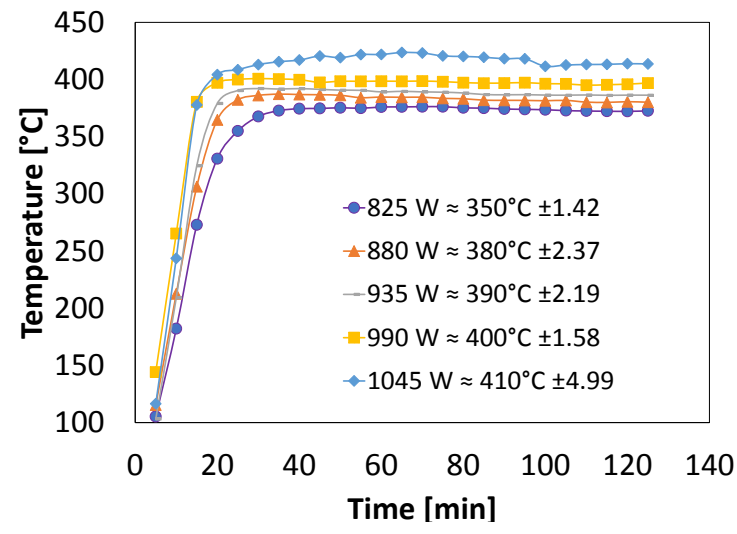

Figure 1. Temperature profile of reactor.

During the experiments, the vapors generated by the thermal cracking reaction exit the reactor through a condenser before entering a liquid-vapor separator. The gas fractions were collected from the top of the separator in a Tedlar plastic bag and the liquid fractions were collected at the bottom of a graduated cylinder, both the gaseous and liquid products were weighed. The volume of liquid products, $V_{L}$, was registered as function of time and transformed to mass of liquid products, $m_{L}$, using the density of the final product.

The mass of gaseous products as function of the reaction time, $m_{G}(t)$, was obtained by multiplying the mass of liquid at the same time, $m_{L}(t)$, by the ratio between the final weight 
of gas, $m_{G f}$, and the final weight of liquid, $m_{L f}$, produced from thermal cracking, as described in Equation 1.

$$
m_{G}(t)=m_{L}(t) \times \frac{m_{G f}}{m_{L f}}
$$

Finally, the mass of reactant, $m_{A}$, at any moment was determined using mass conservation laws. This is used to calculate conversion and yield at the different reaction temperatures.

Characterization Methods. The plastic pellets were characterized with a Cary 630 FTIR Spectrometer from Agilent Technologies which allows the identification of the common functional group composition. 5 grams of pellet sample were used for moisture and ashes analyses. These processes were carried out in a drying oven (ECOSHEL, model FA-45B) at $70^{\circ} \mathrm{C}$ for 48 hours and a high temperature furnace (HYSC, model MF-03) at $550^{\circ} \mathrm{C}$ for 24 hours, respectively. The characterization methods used to analyze the liquid products are based on different ASTM methods. The methods and standards for the characterization are presented in

Table 1.

Table 1. Characterization methods for liquid products.

\begin{tabular}{ccc}
\hline Property & Method & Standard \\
\hline Density & Standard Test Method for Density, Relative & ASTM D-1298 \\
& $\begin{array}{c}\text { Density, or API Gravity of Crude Petroleum and } \\
\text { Liquid Petroleum Products by Hydrometer Method }\end{array}$ & {$[25]$} \\
& & \\
\hline Kinematic & Standard Test Method for Kinematic Viscosity of & ASTM D-445 \\
Viscosity & Transparent and Opaque Liquids (and Calculation & of Dynamic Viscosity) \\
& & \\
\hline Fire Point & Standard Test Method for Flash and Fire Points by & ASTM D-92 \\
& Cleveland Open Cup Tester & [27] \\
\hline
\end{tabular}

A Thermo Scientific model TRACE 1310 Gas Chromatograph with an ISQ 7000 Mass Spectrometer (GC-MS) was used to identify the carbon number of the liquid products. The 
software used was Chromeleon Chromatography Studio software with the NIST MS library. A TG-5MS column (30 m x $0.24 \mathrm{~mm} ; 0.25 \mu \mathrm{m})$ was used for the analyses. The GC oven temperature began at $50{ }^{\circ} \mathrm{C}$ held for $1 \mathrm{~min}$, followed by a $4^{\circ} \mathrm{C} / \mathrm{min}$ ramp up to $280^{\circ} \mathrm{C}$ and kept constant for $10 \mathrm{~min}$. A helium flow rate of $1.2 \mathrm{~mL} / \mathrm{min}$, an injector temperature of $320^{\circ} \mathrm{C}$, a purge flow of $5 \mathrm{~mL} / \mathrm{min}$ and a split flow of $100 \mathrm{~mL} / \mathrm{min}$ were used. The MS works with an electron ionization (EI) system in the range of full scan. The ion source was kept at $230{ }^{\circ} \mathrm{C}$, while the MS transfer line was kept at $320{ }^{\circ} \mathrm{C}$. The gaseous product was characterized using a Thermo Scientific Gas Chromatograph (GC) model TRACE 1310 with a Flame Ionization Detector (FID). A TG Bond Q Thermo Scientific (15m x $0.53 \mathrm{~m} ; 0.20 \mu \mathrm{m})$ column was used. The GC oven temperature began at $30{ }^{\circ} \mathrm{C}$ followed by a $10^{\circ} \mathrm{C} / \mathrm{min}$ ramp up to $200^{\circ} \mathrm{C}$ and held for $8 \mathrm{~min}$. A helium flow rate of $2.1 \mathrm{~mL} / \mathrm{min}$, an injector temperature of $250^{\circ} \mathrm{C}$, a purge flow of $5 \mathrm{~mL} / \mathrm{min}$ and a split flow of $21 \mathrm{~mL} / \mathrm{min}$ were used. The temperature in the detector (FID) was set at $200^{\circ} \mathrm{C}$. The gases were identified by comparison with the standards gases of chromatograms Scott Cat. No. 22566 and Scott Cat. No. 501662.

Kinetic Analysis. The thermal cracking reaction of plastic pellets is described in Equation 1. The pellets $(\boldsymbol{A})$ produce the desired liquid (B) and gaseous $(\boldsymbol{C})$ products.

$$
A \rightarrow \mathrm{B}+\mathrm{C}
$$

The model used for the kinetic study of cracking reactions of plastic pellets is based on the mass balance of a batch reactor and it is presented in Equation 2, where the reaction rate is a function of the mass of reactant.

$$
R_{A}=\frac{d m_{A}}{d t}
$$

The rate of consumption of the plastic pellets, $R_{A}$, is represented by the power law expression, as presented in Equation 3; by applying the logarithm, it can be linearized to obtain the kinetic parameters. 


$$
R_{A}=-k \cdot m_{A}^{n}
$$

Where the kinetic constant $(k)$ and the reaction order $(n)$ were determined using the integral and differential methods [28], respectively. The activation energy $\left(E_{a}\right)$ and pre-exponential factor $\left(k_{o}\right)$, are obtained by the linear expression of the Arrhenius law as presented in Equation 5.

$$
\ln (k)=\ln \left(k_{o}\right)-\frac{E_{a}}{R T}
$$

\section{RESULTS AND DISCUSSIONS}

Characterization of Raw Materials. FTIR was performed to determine the purity of the raw materials and the potential of conversion of plastics into liquid fuel. According to the structure of each polymer, the peaks of the infrared spectra are found in specific ranges of wavenumber, which identify the main functional groups. The PP, HDPE and LDPE infrared spectra within a wavenumber range $600-4000 \mathbf{c m}^{-1}$ are observed in Figure 2. The peaks between 3100 and $2600 \mathbf{c m}^{\mathbf{- 1}}$ infer the presence of aliphatic hydrocarbons $\left(\boldsymbol{C}-\boldsymbol{H}_{\text {stretch }}\right)$ such as methyl (2957 and $\left.2870 \mathbf{c m}^{-1}\right)$ and methylene $\left(2922 \mathbf{c m}^{-1}\right)$ [29]. The peaks at 1600 and $1100 \mathbf{c m}^{-1}$ can be identified as alkenes $\left(\boldsymbol{C}=\boldsymbol{C}_{\text {stretch }}\right)$ which confirm the presence of olefins and the peaks between 1100 and $600 \mathbf{c m}^{-1}$ can correspond to alkenes and aromatics $\left(\boldsymbol{C}-\boldsymbol{H}_{\boldsymbol{b e n d}}\right)$ [30]. As observed, the long chains of polymers are the raw material with a great potential to break down into simpler molecules such as liquid fuel. 


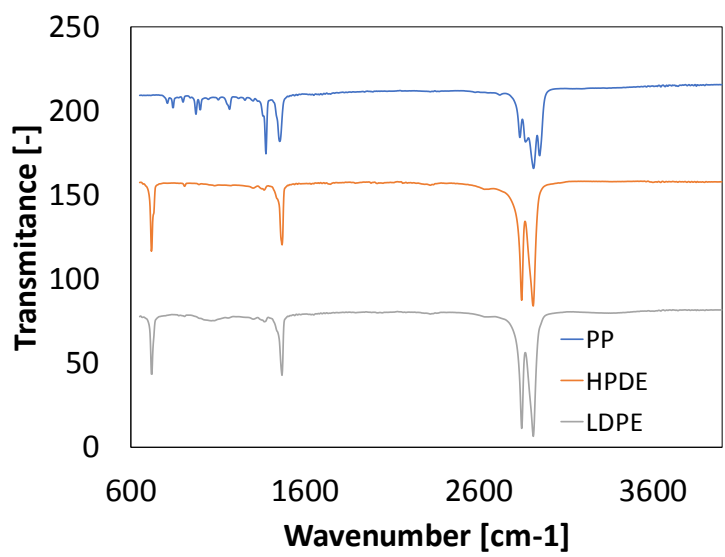

Figure 2. Infrared spectra of primary PP, HDPE and LDPE plastic pellets. Also, moisture and ash content were analyzed to establish the physical properties of the plastics. Table 2 indicates the percentage of each parameter for the plastics used in the thermal cracking reaction.

Table 2. Ash and moisture content of primary PP, HDPE and LDPE plastics

\begin{tabular}{ccc}
\hline Plastic Type & Ash [\%] & Moisture [\%] \\
\hline PP & 0.084 & 0.039 \\
\hline HDPE & 0.073 & 0.045 \\
\hline LDPE & 0.097 & 0.069 \\
\hline
\end{tabular}

Investigation of Temperature on Cracking Process. In this section the dependence of the product distribution with the cracking temperature are presented. The experimental data are available in the Supporting Information. Figure 3 shows the distribution of the mass of reactant, $\boldsymbol{m}_{\boldsymbol{A}}$, as a function of time at different reaction temperatures for each plastic.

Figure 3 a), represents the behavior of PP. At cracking temperature of $360^{\circ} \mathrm{C}$, the reaction rate is small, and no significant liquid and gaseous products can be observed, while at a cracking temperature of $370-375^{\circ} \mathrm{C}$, the mass of reactant decreases substantially with time, while the desired products are obtained.

Figure 3 b) and c) show that for HDPE and LDPE plastics conversions between $70 \%-85 \%$ are reached at cracking temperatures in the range between $390-400^{\circ} \mathrm{C}$ and $380-390^{\circ} \mathrm{C}$, 
respectively. Unlike PP and LDPE, HDPE requires a higher temperature for the cracking reaction. This behavior of HDPE plastics is due to the resistance of the carbon bonds in its macromolecular structure. HDPE is a long-chain polymer with low ramifications in its structure and a high degree of crystallinity. Therefore, it has high resistance to thermal degradation [31, 32]. LDPE, on the other hand, has a branched structure and low crystallinity, so its bonds are easily broken by heat. As well as PP, as it has a $\left(-\boldsymbol{C H}_{\mathbf{3}}\right)$ group and low crystallinity, which requires lower temperature to break and a shorter reaction time [30].
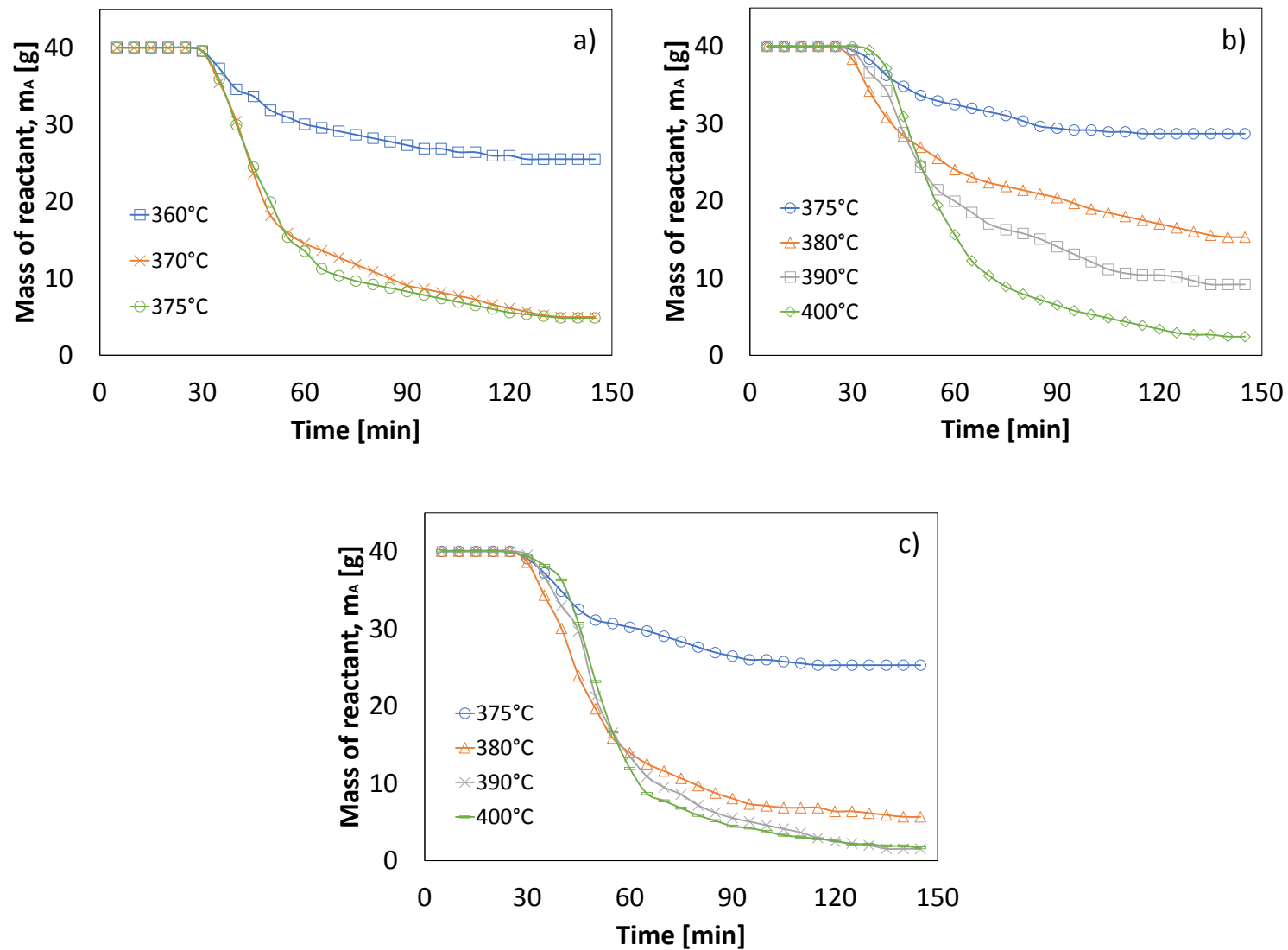

Figure 3. Mass of reactant consumed during the thermal cracking reaction: (a) PP, (b) HDPE, (c) LDPE.

Figure 4 shows the yield of the liquid fraction as it increases linearly at higher temperatures. In the case of PP, the yield increases from 26 to $62 \%$ as the temperature was increased from 
360 to $375^{\circ} \mathrm{C}$. Similarly, the yield increases from 13 to $69 \%$ in HDPE and from 29 to $72 \%$ in LDPE as the temperatures is raised from 375 to $400^{\circ} \mathrm{C}$.

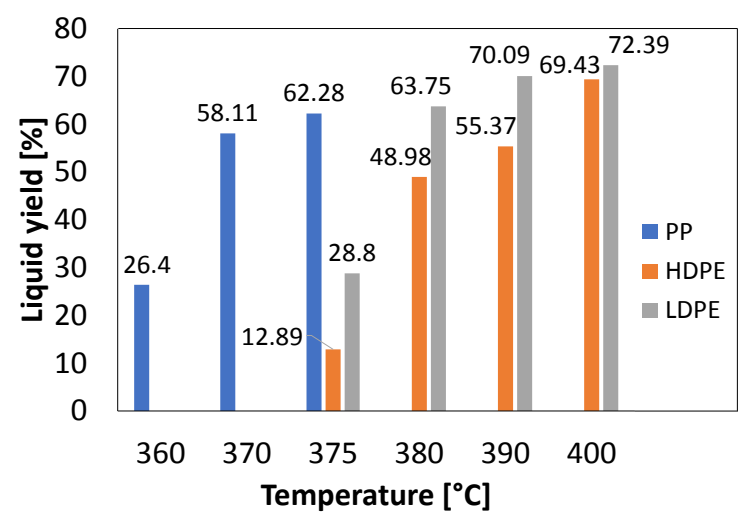

Figure 4. Reaction yield of liquid products for the three plastics as a function of temperature.

The mass balances of the different plastics were established at the optimal reaction temperatures of 375,400 and $390^{\circ} \mathrm{C}$ for PP, HDPE and LDPE, respectively. The optimal temperatures were defined as the ones where approximately $70 \%$ of yield was reached after 120 minutes for each plastic. The weight percentages obtained from the mass balances of the different cracking processes are shown in Table 3. The temperature has not affected the selectivity of the desired liquid products, therefore its effects are negligible [33]. The results show that the thermal cracking of LDPE has the highest yield for the desired liquid products.

Table 3. Mass balance obtained for the cracking reactions of plastic pellets.

\begin{tabular}{ccccc}
\hline $\begin{array}{c}\text { Plastic } \\
\text { Type }\end{array}$ & $\begin{array}{c}\text { Liquid } \\
\text { fraction [\%] }\end{array}$ & $\begin{array}{c}\text { Gaseous } \\
\text { fraction [\%] }\end{array}$ & Residue [\%] & Losses [\%] \\
\hline PP & 68.83 & 0.65 & 22.47 & 8.05 \\
\hline HDPE & 73.47 & 0.025 & 11.22 & 15.29 \\
\hline LDPE & 77.77 & 1.02 & 10.12 & 11.09 \\
\hline
\end{tabular}


Kinetic Analysis. The kinetic rate law of the thermal cracking was estimated using the data from three different temperatures for PP (i.e. $360,370,375^{\circ} \mathrm{C}$ ) and four for HDPE and LDPE (i.e. $375,380,390,400^{\circ} \mathrm{C}$ ). Figure 5 a) shows the linearized differential model of the power law kinetic expression of PP in a batch system, where a first order reaction was found. This order was then applied for the definition of the kinetic constant using the linearized integral method as shown in Figure 5 b). These values are used in the Arrhenius equation to determine the activation energy, $\boldsymbol{E}_{\boldsymbol{a}}$, and the pre-exponential factor, $\boldsymbol{k}_{\boldsymbol{o}}$ as shown in Figure $\mathbf{5}$ c). The same process was performed for HDPE and LDPE plastic pellets and the results are presented in the Supplemental Information.
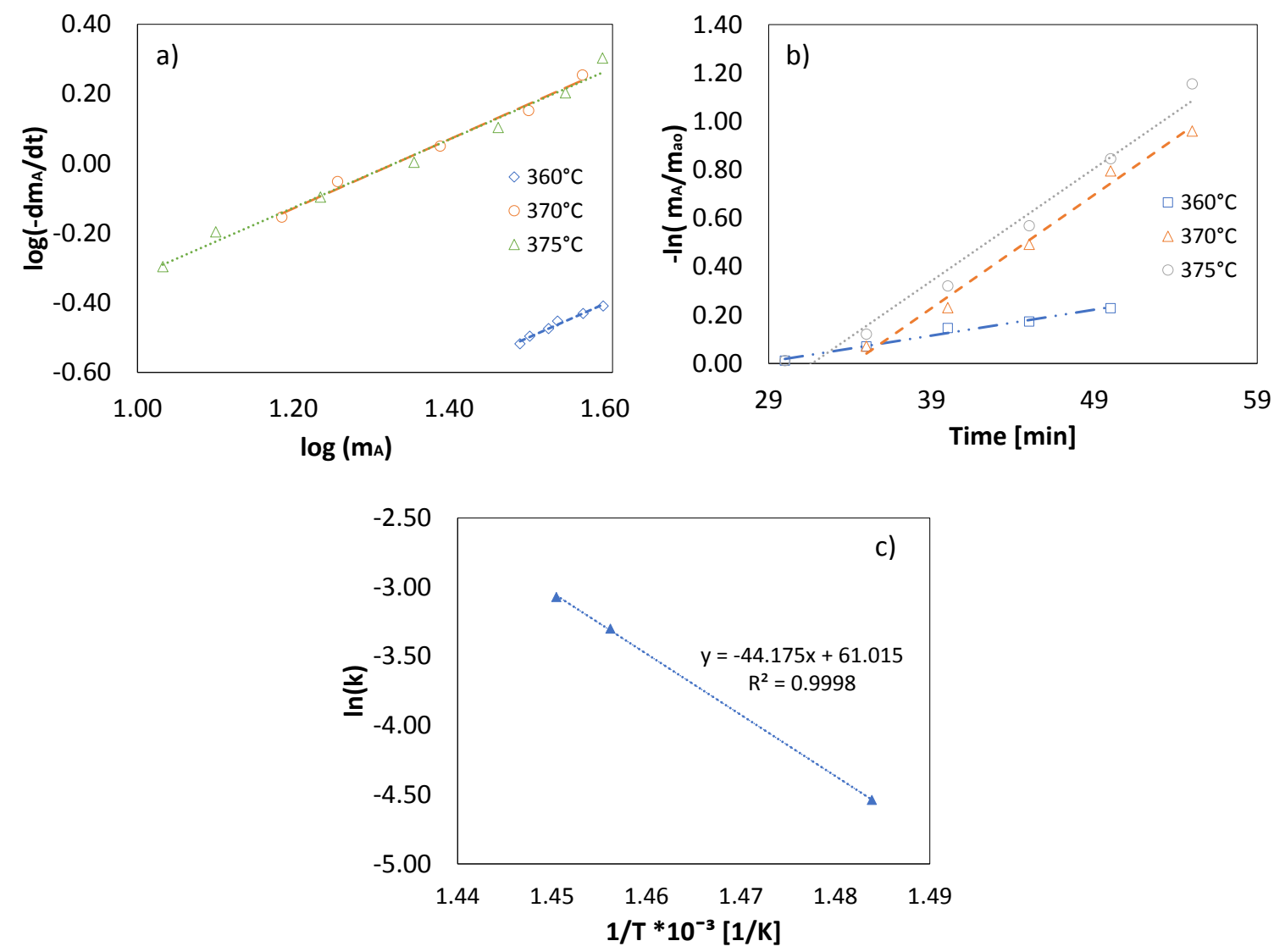

Figure 5. Graphical methods for the kinetic analysis of the thermal cracking of PP determining: (a) reaction order by differential method, (b) kinetic constant by integral method, and (c) activation energy and pre-exponential factor by the linearized Arrhenius law 
Table 4 shows the results obtained for the kinetic analysis of the three plastics PP, HDPE and LDPE using both kinetic methods. As observed, the reaction order for the thermal cracking of all plastics can be defined as 1 . Also, as expected, an increase in the value of the kinetic constant $\boldsymbol{k}$ can be observed with the temperature, exhibiting a linear dependence [33]. The activation energy of PP is $367.28 \mathrm{~kJ} / \mathrm{mol}$, while for HDPE and LDPE higher values of 453.37 and $457.96 \mathrm{~kJ} / \mathrm{mol}$ are found, respectively. These results are comparable with the values reported in studies by Yan et al. [29] and Hazrat et al. [16], where the reported activation energies are 362.6, 342.95 and $413 \mathrm{~kJ} / \mathrm{mol}$ for PP, HDPE and LDPE, respectively. Thus, the data predicted by the model is consistent with the literature values with a percentage error equal to 1.3, 32.2 and $10.9 \%$ for PP, HDPE and LDPE, respectively. Also, it can be established that PP is a less stable polyolefin that can be cracked at a lower initial temperature than HDPE and LDPE. The results obtained show that indeed the activation energy of virgin plastic is higher than plastic waste, this is because virgin plastic degrades at a higher initial temperature while waste plastics can easily degrade and may favor the mild condition [29].

Table 4. Kinetic parameters obtained for the experimental data.

\begin{tabular}{|c|c|c|c|c|c|c|c|c|c|}
\hline \multirow{2}{*}{$\begin{array}{l} \\
\text { Plastic } \\
\text { Type }\end{array}$} & \multirow[b]{2}{*}{$\begin{array}{c}\text { Temp } \\
{\left[{ }^{\circ} \mathrm{C}\right]}\end{array}$} & \multicolumn{2}{|c|}{$\begin{array}{c}\text { Differential } \\
\text { analysis }\end{array}$} & \multicolumn{2}{|c|}{$\begin{array}{l}\text { Integral } \\
\text { analysis }\end{array}$} & \multicolumn{4}{|c|}{ Kinetic parameters } \\
\hline & & $\begin{array}{c}n \\
{[-]}\end{array}$ & $R^{2}$ & {$\left[\frac{1}{k}\right]$} & $R^{2}$ & {$\left[\frac{1}{k}\right]$} & $\begin{array}{c}k_{o} \\
{\left[\left(\frac{m o l}{m L}\right) \min ^{-1}\right]}\end{array}$ & {$\left[\begin{array}{c}E_{a} \\
k J \\
m o l\end{array}\right]$} & $R^{2}$ \\
\hline \multirow[t]{3}{*}{ PP } & 360 & 0.9895 & 0.9782 & 0.0107 & 0.9816 & $3.13 \mathrm{E}-2 \pm 0.02$ & $3.15 E+26$ & 367.28 & 0.9998 \\
\hline & 370 & 0.9917 & 0.9888 & 0.0369 & 0.9898 & & & & \\
\hline & 375 & 0.9780 & 0.9861 & 0.0464 & 0.9861 & & & & \\
\hline \multirow[t]{4}{*}{ HDPE } & 375 & 0.9449 & 0.9949 & 0.0042 & 0.9954 & $2.24 \mathrm{E}-2 \pm 0.02$ & $3.14 \mathrm{E}+31$ & 453.37 & 0.9014 \\
\hline & 380 & 0.9602 & 0.9882 & 0.0129 & 0.9882 & & & & \\
\hline & 390 & 1.3161 & 0.9920 & 0.0295 & 0.9902 & & & & \\
\hline & 400 & 0.9859 & 0.9872 & 0.0431 & 0.9855 & & & & \\
\hline \multirow[t]{4}{*}{ LDPE } & 375 & 0.9786 & 0.9915 & 0.0118 & 0.9909 & $1.95 \mathrm{E}-1 \pm 0.30$ & $1.48 \mathrm{E}+32$ & 457.96 & 0.9934 \\
\hline & 380 & 1.0119 & 0.9946 & 0.0406 & 0.9935 & & & & \\
\hline & 390 & 0.9807 & 0.9960 & 0.0472 & 0.9853 & & & & \\
\hline & 400 & 1.0733 & 0.9932 & 0.6815 & 0.9960 & & & & \\
\hline
\end{tabular}


Characterization of Cracking Products. The liquid and gaseous products of the cracking process at the optimal condition were characterized for $\mathrm{PP}\left(858 \mathrm{~W} / 375^{\circ} \mathrm{C}\right), \mathrm{HDPE}$ $\left(990 \mathrm{~W} / 400^{\circ} \mathrm{C}\right)$ and LDPE $\left(935 \mathrm{~W} / 390^{\circ} \mathrm{C}\right)$. The physical properties using ASTM methods [2527] of liquid product are shown and compared with diesel and gasoline standards in Table 5. As seen, the density, API degree and flash point of PP product are in the gasoline range. While the kinematic viscosity, density, API degree and flash point of HDPE and LDPE are close to diesel range.

Table 5. Characterization of liquid cracking products.

\begin{tabular}{ccccc}
\hline & $\begin{array}{c}\text { Density } \\
{\left[\mathrm{g} / \mathrm{cm}^{3}\right]}\end{array}$ & $\begin{array}{c}\text { API degree } \\
{[\mathrm{deg}]}\end{array}$ & $\begin{array}{c}\text { Kinematic } \\
\text { viscosity }[\mathrm{cSt}]\end{array}$ & $\begin{array}{c}\text { Flash } \\
\text { point }\left[{ }^{\circ} \mathrm{C}\right]\end{array}$ \\
\hline PP - Product & 0.75 & 57.28 & 1.06 & $<24.00$ \\
\hline HDPE - Product & 0.78 & 50.45 & 2.66 & 55.33 \\
\hline LDPE - Product & 0.79 & 47.20 & 2.73 & 64.67 \\
\hline Gasoline & $0.74-0.75$ & $57.48-59.54$ & $0.54-0.59$ & -40 \\
\hline Diesel & $0.85-0.87$ & $29.70-33.40$ & $2.0-5.0$ & $>51$ \\
\hline
\end{tabular}

The composition of the liquid product was also analyzed qualitatively using a GC-MS and compared with chromatograms from gasoline and diesel standards. The standard's chromatograms are presented for gasoline in Figure 6 a) and for diesel in Figure 6 c).

Figure 6 b), shows the liquid products obtained from PP, where short chains of hydrocarbons between $C_{9}-C_{19}$ are identified. This range is also observed in the chromatogram of gasoline standard. In previous studies of the thermal cracking of virgin polypropylene, a similar distribution of carbon number among $C_{6}-C_{12}$ was identified, indicating a significant presence of alkenes [29]. The greater number of carbons with double bonds is due to the presence of the $\mathrm{CH}_{3}$ - group in the PP structure [29].

On the other hand, Figure $6 \mathrm{~d}$ ) and e) present the chromatograms of HDPE and LDPE liquid products with hydrocarbon chains between $C_{9}-C_{27}$ and $C_{8}-C_{27}$, respectively. The results obtained are in a similar range of the diesel's chromatogram and show the same sort of bell 
distribution. Some investigations indicate that the hydrocarbon distribution of HDPE and LDPE are found among $C_{5}-C_{32}$ and $C_{6}-C_{30}$, respectively [29, 34, 35]. Additionally, the distribution of double peaks throughout the chromatogram indicates the presence of n-alkane and n-alkene (1-olefins) [36]. These results confirm that from the thermal cracking of PP lighter fractions corresponding to gasoline are obtained, unlike HDPE and LDPE where heavy fractions such as diesel are obtained. 

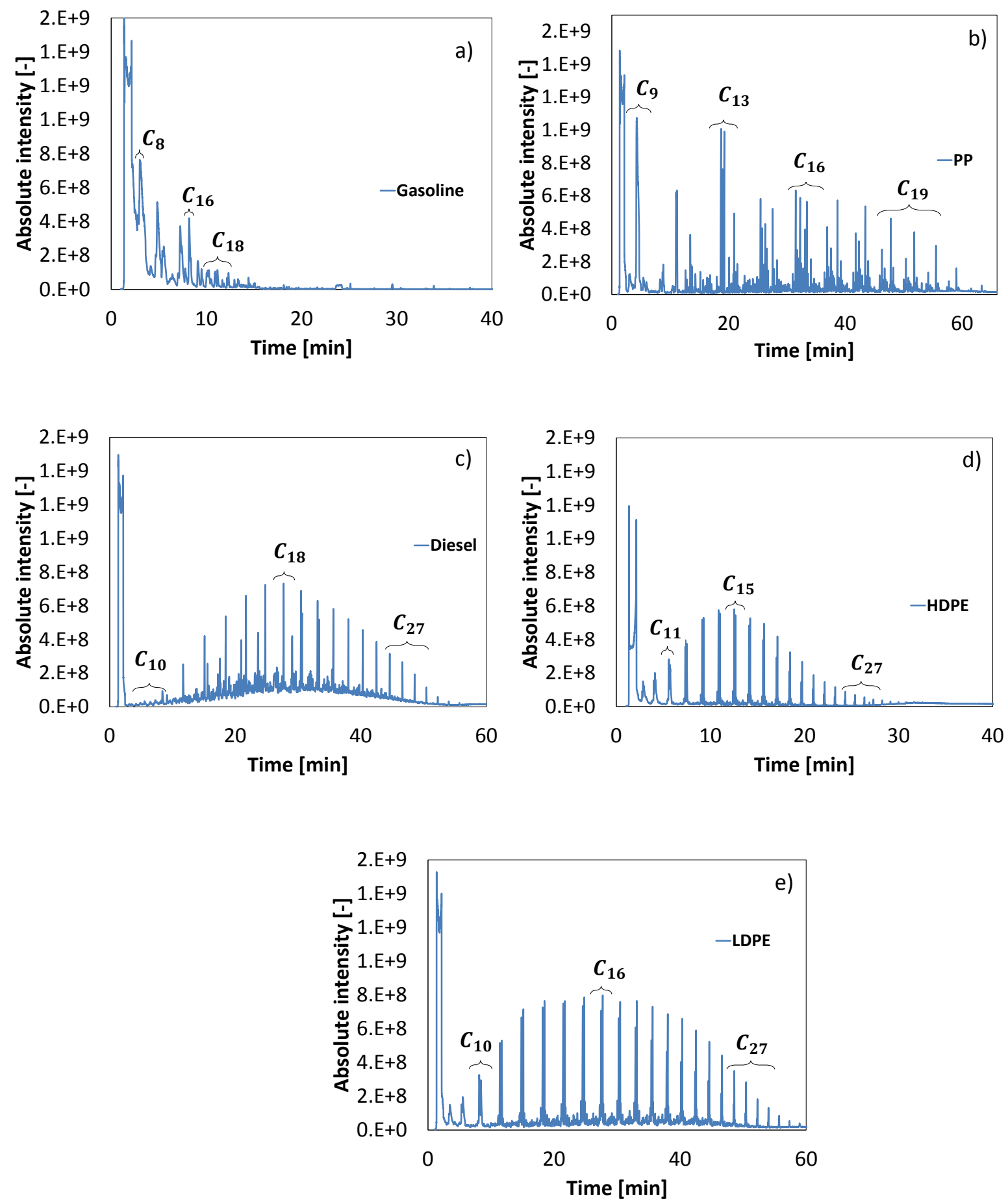

Figure 6. GS-MS chromatograms of (a) gasoline, (b) liquid fractions of PP, (c) diesel, (d) liquid fractions of HDPE, (e) liquid fractions of LDPE.

The gaseous products were analyzed by GC - FID detector. The chromatograms of PP and LDPE are observed in Figure 7, the compounds were determined based on retention time. In all the samples, three peaks are identified between the retention time from 1 to 8 minutes 
corresponding to $C_{1}-C_{2}$ compounds such as methane, ethane, ethylene and acetylene. On the other hand, peaks 4 to 7 are represented by $C_{3}-C_{4}$ bonds such as propane, propylene and nbutane in retention times of 10 to 15 minutes. HDPE gas samples were not analyzed since the gas could not be collected. This is confirmed by the low yield presented in the mass balance of HDPE in Table 3 where it is lower than $0.5 \%$.

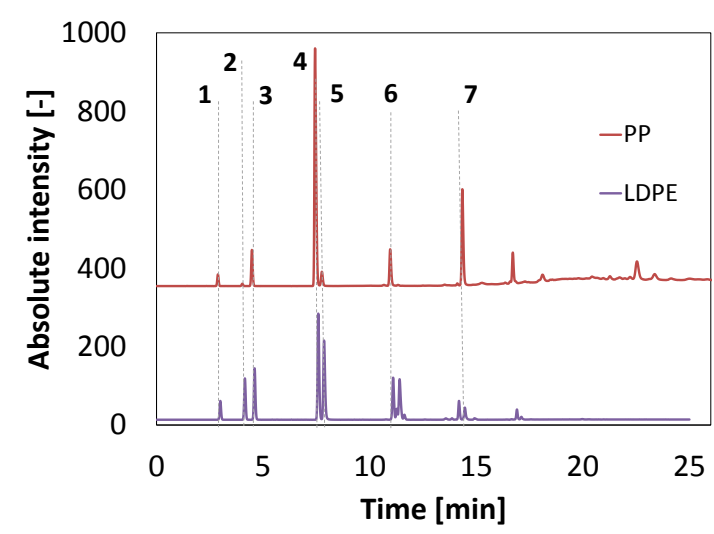

Figure 7. Chromatogram of the gas fractions of PP and LDPE. Peaks: 1 Methane, 2 Ethane, 3 Ethylene, 4 Acetylene, 5 Propane, 6 Propylene, 7 n-Butane.

Reaction Mechanism. The mechanism of thermal decomposition of polymers is arbitrary, the probability of breaking under the influence of heat is very similar for any bond in the molecule. Therefore, the polymers decompose into a large number of paraffinic and olefinic compounds. The analysis of the gaseous and liquid products agrees with the radical chain mechanism proposed by Yan et al [29, 37].

In the initiation phase, two free radicals are formed due to the breaking of the chain. The cracking may occur either at the ends of the chain or in the middle. Therefore, these products could include free methyl radicals. The propagation phase consists of a sequence of $\mathrm{H}$ abstractions and $\beta$ scissions. The $\mathrm{H}$-abstraction can be intermolecular, where a free radical takes a hydrogen from a different molecule, or intramolecular, where the hydrogen abstraction occurs inside in the same radical followed by $\beta$-scission which originates an alkene and a free radical. 
Finally, the termination phase occurs through the combination of two radicals [35-40]. The proposed reaction mechanism for PP, HDPE and LDPE are presented in Figure 8.

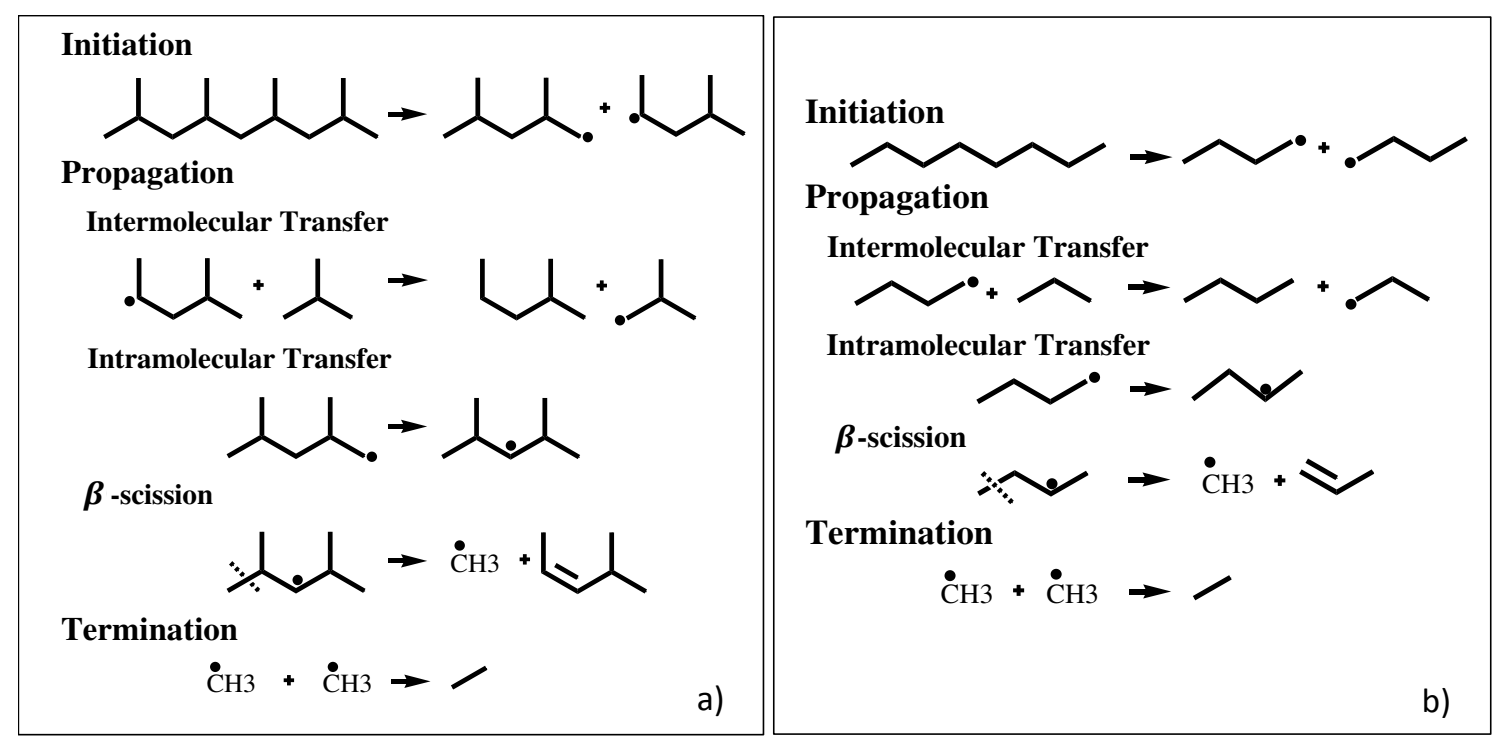

Figure 8. Reaction mechanism of thermal cracking (a) PP and (b) HDPE/LDPE

All cracking reactions start with the initiation reaction and finish with the termination. The product distribution depends on the pathway followed for the propagation reaction. The research of Levine et al [39] and Gao et al [38] indicate that $\beta$-scission is a dominant reaction to form alkenes and the intermolecular hydrogen abstraction to form alkanes. As mentioned, a major presence of alkenes was identified in the liquid products obtained from the PP, establishing intramolecular transfer followed by $\beta$-scission as the main reaction for PP cracking. On the other hand, the presence of alkanes and olefins in the liquid product of HDPE and LDPE, can be explained by two competing reaction pathways, namely the same intramolecular transfer followed by $\beta$-scission and the intermolecular hydrogen transfer responsible for the alkanes production [29]. Finally, the composition of the gaseous products can be explained by $\beta$-scission forming the alkenes ethylene and propylene, while $\mathrm{H}$ abstraction favor aliphatic compounds such as methane, ethane, propane and n-butane [29]. 
Using this simplified reaction mechanism consisting of 5 steps, the product distribution of the thermal cracking reaction of PP, HDPE and LDPE can be explained.

\section{CONCLUSION}

In this investigation, the thermal cracking of primary plastic pellets of PP, HDPE, and LDPE was studied at different reaction temperatures. The results show that the highest cracking yield of $72 \%$ is obtained with LDPE at $390^{\circ} \mathrm{C}$. The yield obtained for PP is $62 \%$ at $375^{\circ} \mathrm{C}$, while HDPE requires the highest temperature and reaches a yield of $69 \%$ at $400^{\circ} \mathrm{C}$. The physical properties of the final products obtained by the cracking processes of the different plastics shows that with a further post-treatment step PP can meet the necessary requirements for gasoline, while HDPE and LDPE products show similar characteristics to diesel.

The kinetic study shows that reactions of the three types of plastics are first order. In addition, the lowest activation energy belongs to PP with a value of $367.28 \mathrm{~kJ} / \mathrm{mol}$, followed by HDPE with $453.37 \mathrm{~kJ} / \mathrm{mol}$ and LDPE with $457.96 \mathrm{~kJ} / \mathrm{mol}$. Finally, the reaction mechanisms of thermal decomposition of polymers are based on chain reactions with radical formation, where $\beta-$ scission is the main reaction to form alkene compounds and intermolecular hydrogen abstraction to form alkane compounds in the final products.

The results obtained from the thermal cracking of the most abundant plastics, namely PP, HDPE and LDPE, show very promising results in their capability to form alternative liquid fuels. To be able to incorporate the products in commercial blends, further investigations on post-treatments, heat value and stability are necessary. Also, the gaseous and liquid products of the cracking reaction can be used as chemical precursors or reincorporated into refining processes to valorize this residue as secondary chemicals. 
- AUTHOR INFORMATION

\section{Corresponding Author}

Daniela Almeida Streitwieser - Institute for the Development of Alternative Energies and Materials IDEMA, Department of Chemical Engineering, Universidad San Francisco de Quito USFQ, EC 170901 Quito, Ecuador

*E-mail: dalmeida@usfq.edu.ec.

\section{- AUTHOR CONTRIBUTIONS}

Conceptualization: [Daniela Almeida Streitwieser]; Methodology: [Yuliana Rodríguez Lamar], [José Noboa]. Formal analysis and investigation: [Yuliana Rodríguez Lamar], [Andrés S. Torres Miranda]. Writing - original draft preparation: [Yuliana Rodríguez Lamar], [José Noboa], [Andrés S. Torres Miranda]. Writing - review and editing: [[Yuliana Rodríguez Lamar], [José Noboa], [Daniela Almeida Streitwieser]. Funding acquisition: [Daniela Almeida Streitwieser]. Resources: [Yuliana Rodríguez Lamar], [José Noboa], [Daniela Almeida Streitwieser]. Supervision: [Daniela Almeida Streitwieser], [José Noboa].

\section{- ACKNOWLEDGMENTS}

This research has been supported by the USFQ Poli Grant 2017. Grant number HUBI 5508.

\section{- SUPPORTING INFORMATION}

Supporting information corresponds to the experimental data and its application for determining the differential and integral methods as well as the Arrhenius analysis for HDPE and LDPE.

\section{- DECLARATIONS}

All authors confirm that they don't have any conflict of interests regarding sources of funding, financial or non-financial interests. This research did not involve humans and/or animals, nor required consent of involved human participants, 


\section{- REFERENCES}

1. Adnan, Shah J, Jan MR (2017) Recovery of Valuable Hydrocarbons from Waste Polystyrene Using Zinc Supported Catalysts. J Polym Environ 25:759-769. https://doi.org/10.1007/s10924-016-0858-4

2. Monteiro RCP, Ivar do Sul JA, Costa MF (2018) Plastic pollution in islands of the Atlantic Ocean. Environ Pollut 238:103-110. https://doi.org/10.1016/j.envpol.2018.01.096

3. Ritchie H, Roser M (2020) Plastic Pollution. OurWorldInData.org 115-147. https://doi.org/10.1142/9781786347435_0005

4. Andrady AL, Neal MA (2009) Applications and societal benefits of plastics. Philos Trans R Soc B Biol Sci 364:1977-1984. https://doi.org/10.1098/rstb.2008.0304

5. Plastics Europe (2019) Plastics - the Facts 2019. An Analysis of European Plastics Production, Demand and Waste Data. Bruselas, Belgica

6. Cheng L, Gu J, Wang Y, et al (2020) Polyethylene high-pressure pyrolysis: Better product distribution and process mechanism analysis. Chem Eng J 385:123866. https://doi.org/10.1016/j.cej.2019.123866

7. Martínez Urreaga J, González-Sánchez C, Martínez-Aguirre A, et al (2015) Sustainable eco-composites obtained from agricultural and urban waste plastic blends and residual cellulose fibers. J Clean Prod 108:377-384. https://doi.org/10.1016/j.jclepro.2015.06.001

8. Thompson RC, Moore CJ, Saal FSV, Swan SH (2009) Plastics, the environment and human health: Current consensus and future trends. Philos Trans R Soc B Biol Sci 364:2153-2166. https://doi.org/10.1098/rstb.2009.0053

9. de Camargo RV, Saron C (2020) Mechanical-Chemical Recycling of Low-Density Polyethylene Waste with Polypropylene. J Polym Environ 28:794-802. https://doi.org/10.1007/s10924-019-01642-5

10. Patil L, Varma AK, Singh G, Mondal P (2018) Thermocatalytic Degradation of High Density Polyethylene into Liquid Product. J Polym Environ 26:1920-1929. https://doi.org/10.1007/s10924-017-1088-0

11. Eriksson O, Finnveden G (2009) Plastic waste as a fuel - CO2-neutral or not? Energy Environ Sci 2:907-914. https://doi.org/10.1039/b908135f

12. Mrowiec B (2017) Plastic pollutants in water. Ios-Pib 28:51-55. https://doi.org/10.1515 /OsZn-2017-0030

13. Lebreton LCM, Van Der Zwet J, Damsteeg JW, et al (2017) River plastic emissions to the world's oceans. Nat Commun 8:1-10. https://doi.org/10.1038/ncomms 15611

14. Leal Filho W, Saari U, Fedoruk M, et al (2019) An overview of the problems posed by plastic products and the role of extended producer responsibility in Europe. J Clean Prod 214:550-558. https://doi.org/10.1016/j.jclepro.2018.12.256

15. Huysman S, De Schaepmeester J, Ragaert K, et al (2017) Performance indicators for a circular economy: A case study on post-industrial plastic waste. Resour Conserv Recycl 120:46-54. https://doi.org/10.1016/j.resconrec.2017.01.013 
16. Hazrat MA, Rasul MG, Khan MMK (2015) A study on thermo-catalytic degradation for production of clean transport fuel and reducing plastic wastes. Procedia Eng 105:865-876. https://doi.org/10.1016/j.proeng.2015.05.108

17. Ajibola AA, Omoleye JA, Efeovbokhan VE (2018) Catalytic cracking of polyethylene plastic waste using synthesised zeolite Y from Nigerian kaolin deposit. Appl

Petrochemical Res 8:211-217. https://doi.org/10.1007/s13203-018-0216-7

18. Chandrasekaran SR, Kunwar B, Moser BR, et al (2015) Catalytic Thermal Cracking of Postconsumer Waste Plastics to Fuels. 1. Kinetics and Optimization. Energy and Fuels 29:6068-6077. https://doi.org/10.1021/acs.energyfuels.5b01083

19. Das S, Paney S (2007) Pyrolysis and Catalytic Cracking of Municipal Plastic Waste for Recovery of Gasoline Range Hydrocarbons Pyrolysis and Catalytic Cracking of Municipal Plastic Waste for Recovery of Gasoline Range Hydrocarbons. Thesis Natl Inst Technol Rourkela 10-55

20. Ragaert K, Delva L, Van Geem K (2017) Mechanical and chemical recycling of solid plastic waste. Waste Manag 69:24-58. https://doi.org/10.1016/j.wasman.2017.07.044

21. Anuar Sharuddin SD, Abnisa F, Wan Daud WMA, Aroua MK (2017) Energy recovery from pyrolysis of plastic waste: Study on non-recycled plastics (NRP) data as the real measure of plastic waste. Energy Convers Manag 148:925-934. https://doi.org/10.1016/j.enconman.2017.06.046

22. J. P. Vas, . Ramya, A. L. Dsilva, E. Serrao, F. Demash JDD (2017) Production of High Grade Liquid Fuel for CI Engine by Thermo-Catalytic Cracking of Waste Plastic. Energy and Power 7:81-87. https://doi.org/10.5923/j.ep.20170703.05

23. Miandad R, Barakat MA, Aburiazaiza AS, et al (2017) Effect of plastic waste types on pyrolysis liquid oil. Int Biodeterior Biodegrad 119:239-252.

https://doi.org/10.1016/j.ibiod.2016.09.017

24. Vargas DC, Alvarez MB, Hidrobo Portilla A, et al (2016) Kinetic Study of the Thermal and Catalytic Cracking of Waste Motor Oil to Diesel-like Fuels. Energy and Fuels 30:9712-9720. https://doi.org/10.1021/acs.energyfuels.6b01868

25. ASTM:D1298-12b (2012) Standard Test Method for Density, Relative Density, or API Gravity of Crude Petroleum and Liquid Petroleum Products by Hydrometer Method. ASTM Int 99:1-8. https://doi.org/10.1520/D1298-12B.2

26. ASTM D445-06 (2008) Standard Test Method for Kinematic Viscosity of Transparent and Opaque Liquids (and Calculation of Dynamic Viscosity). Man Hydrocarb Anal 6th Ed $1-10$

27. ASTM D92 (2005) Standard Test Method for Flash and Fire Points by Cleveland Open Cup Tester. Annu B ASTM Stand i:3-7. https://doi.org/10.1520/D3638-12.2

28. Levenspiel O (2004) Chemical Reaction Engineering, 3rd ed. México

29. Yan G, Jing X, Wen H, Xiang S (2015) Thermal cracking of virgin and waste plastics of PP and LDPE in a semibatch reactor under atmospheric pressure. Energy and Fuels 29:2289-2298. https://doi.org/10.1021/ef502919f

30. K.Panda A (2018) Thermo-catalytic degradation of different plastics to drop in liquid fuel using calcium bentonite catalyst. Int J Ind Chem 9:167-176. 
https://doi.org/10.1007/s40090-018-0147-2

31. Mills, Nigel; Jenkins, Mike; Kukureka S (2005) Plastics: Microstructure and Engineering Applications. In: Butterworth-Heinemann (ed) 4th ed. p 528

32. Ahmad I, Ismail Khan M, Khan H, et al (2015) Pyrolysis study of polypropylene and polyethylene into premium oil products. Int J Green Energy 12:663-671.

https://doi.org/10.1080/15435075.2014.880146

33. Ding F, Xiong L, Luo C, et al (2012) Kinetic study of low-temperature conversion of plastic mixtures to value added products. J Anal Appl Pyrolysis 94:83-90.

https://doi.org/10.1016/j.jaap.2011.11.013

34. Aguado J, Serrano DP, Escola JM (2008) Fuels from waste plastics by thermal and catalytic processes: A review. Ind Eng Chem Res 47:7982-7992.

https://doi.org/10.1021/ie800393w

35. Rasul Jan M, Shah J, Gulab H (2013) Catalytic conversion of waste high-density polyethylene into useful hydrocarbons. Fuel 105:595-602.

https://doi.org/10.1016/j.fuel.2012.09.016

36. Ballice L, Reimert R (2002) Classification of volatile products from the temperatureprogrammed pyrolysis of polypropylene (PP), atactic-polypropylene (APP) and thermogravimetrically derived kinetics of pyrolysis. Chem Eng Process 41:289-296. https://doi.org/10.1016/S0255-2701(01)00144-1

37. Kurort T, Sekiguchi Y, Ogawa T, et al (2000) Thermal Degradation of Polystyrene. Nippon Kagaku Kaishi 1977:894-901. https://doi.org/10.1246/nikkashi.1977.894

38. Gao Z, Amasaki I, Kaneko T, Nakada M (2003) Calculation of activation energy from fraction of bonds broken for thermal degradation of polyethylene. Polym Degrad Stab 81:125-130. https://doi.org/10.1016/S0141-3910(03)00081-8

39. Levine SE, Broadbelt LJ (2009) Detailed mechanistic modeling of high-density polyethylene pyrolysis: Low molecular weight product evolution. Polym Degrad Stab 94:810-822. https://doi.org/10.1016/j.polymdegradstab.2009.01.031

40. Al-Salem SM, Lettieri P (2010) Kinetic study of high density polyethylene (HDPE) pyrolysis. Chem Eng Res Des 88:1599-1606.

https://doi.org/10.1016/j.cherd.2010.03.012 
Figures

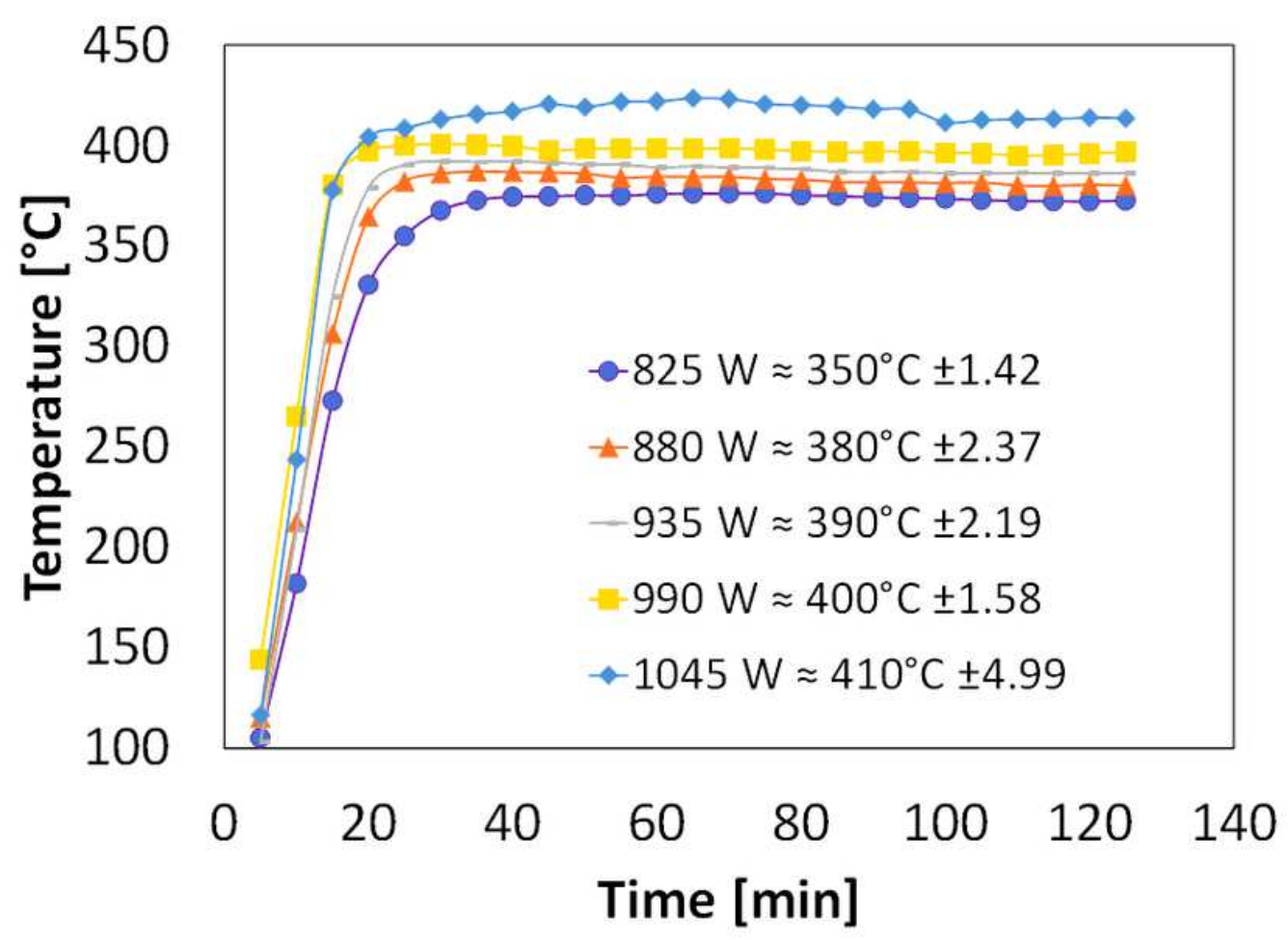

Figure 1

Temperature profile of reactor. 


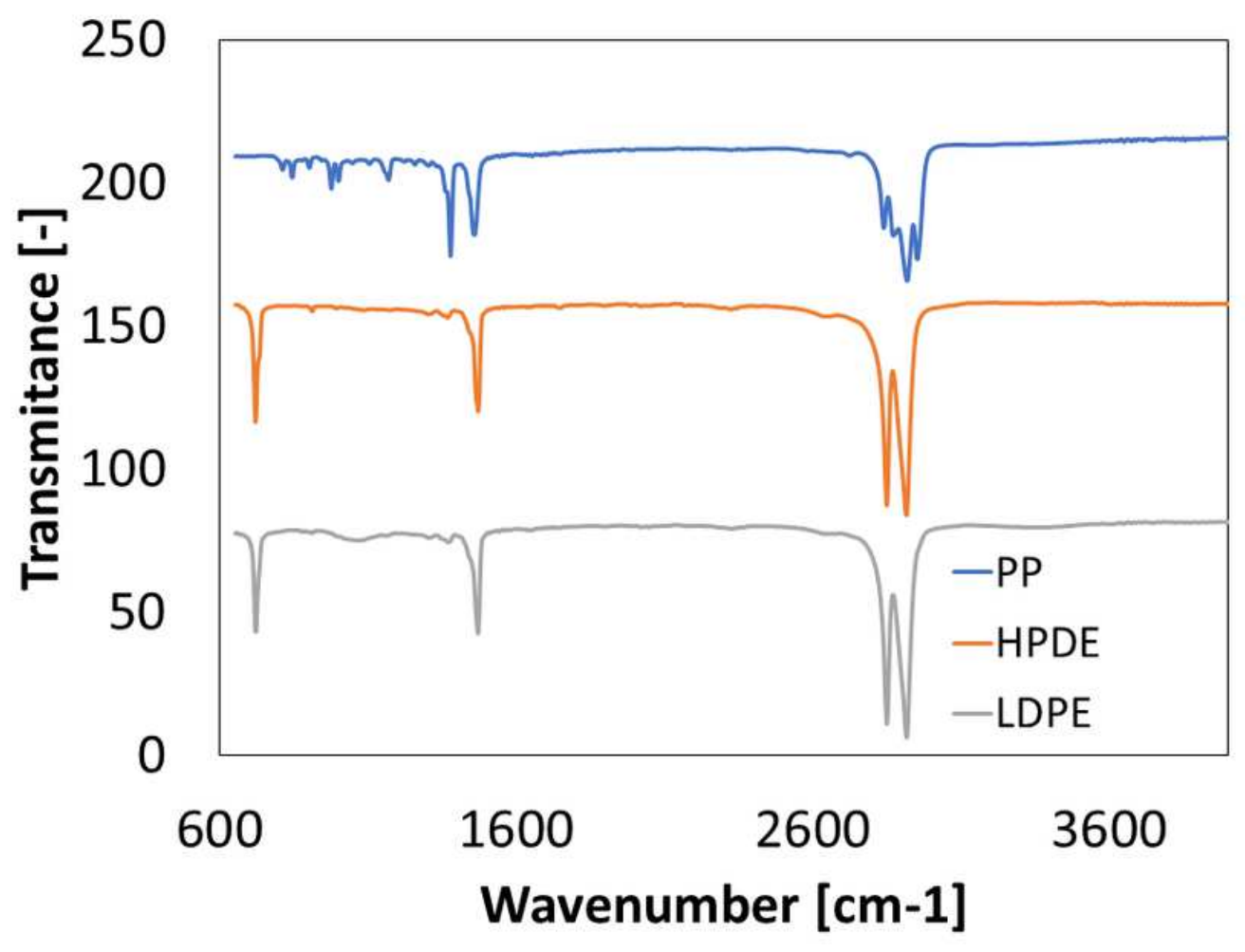

Figure 2

Infrared spectra of primary PP, HDPE and LDPE plastic pellets.
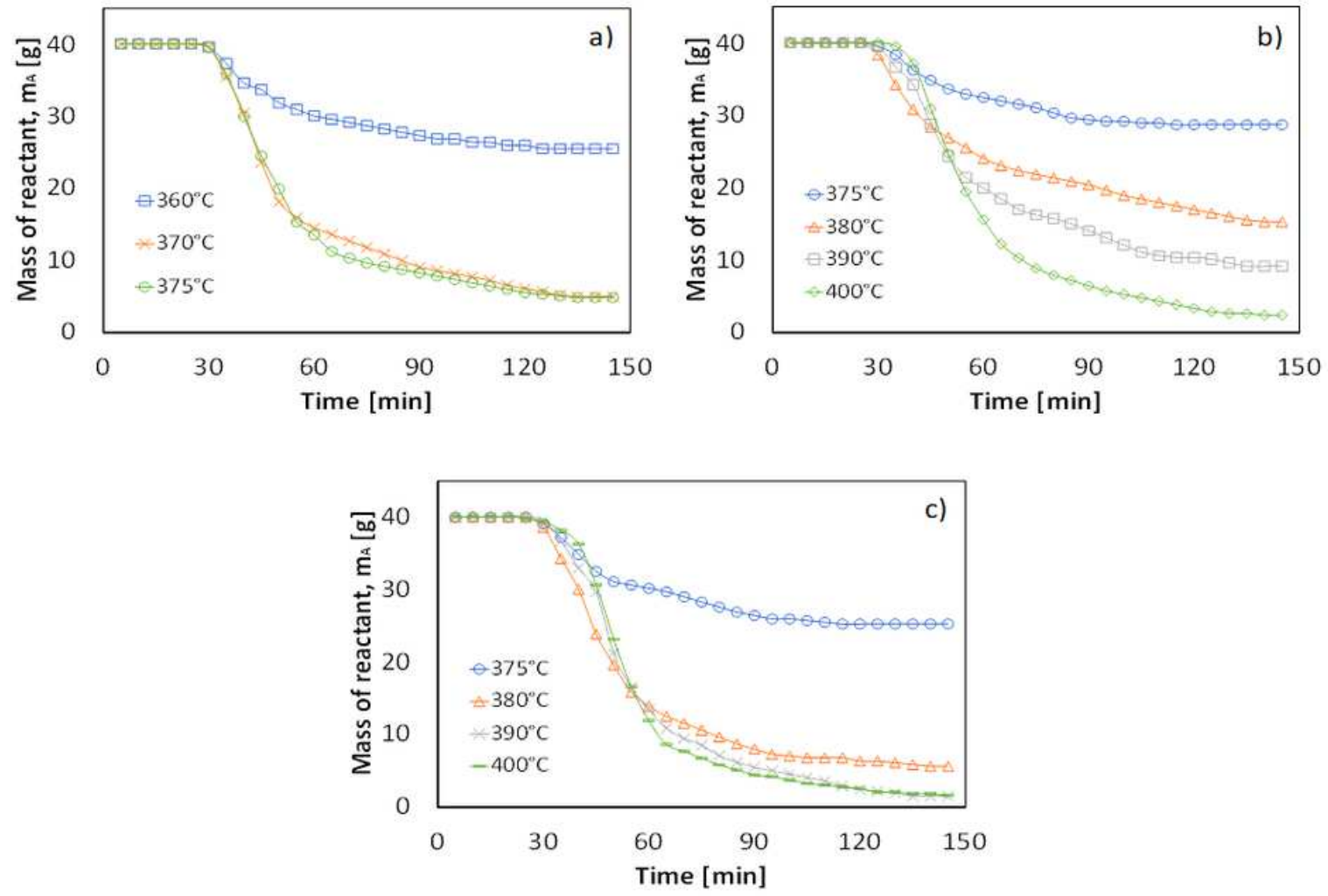
Figure 3

Mass of reactant consumed during the thermal cracking reaction: (a) PP, (b) HDPE, (c) LDPE.

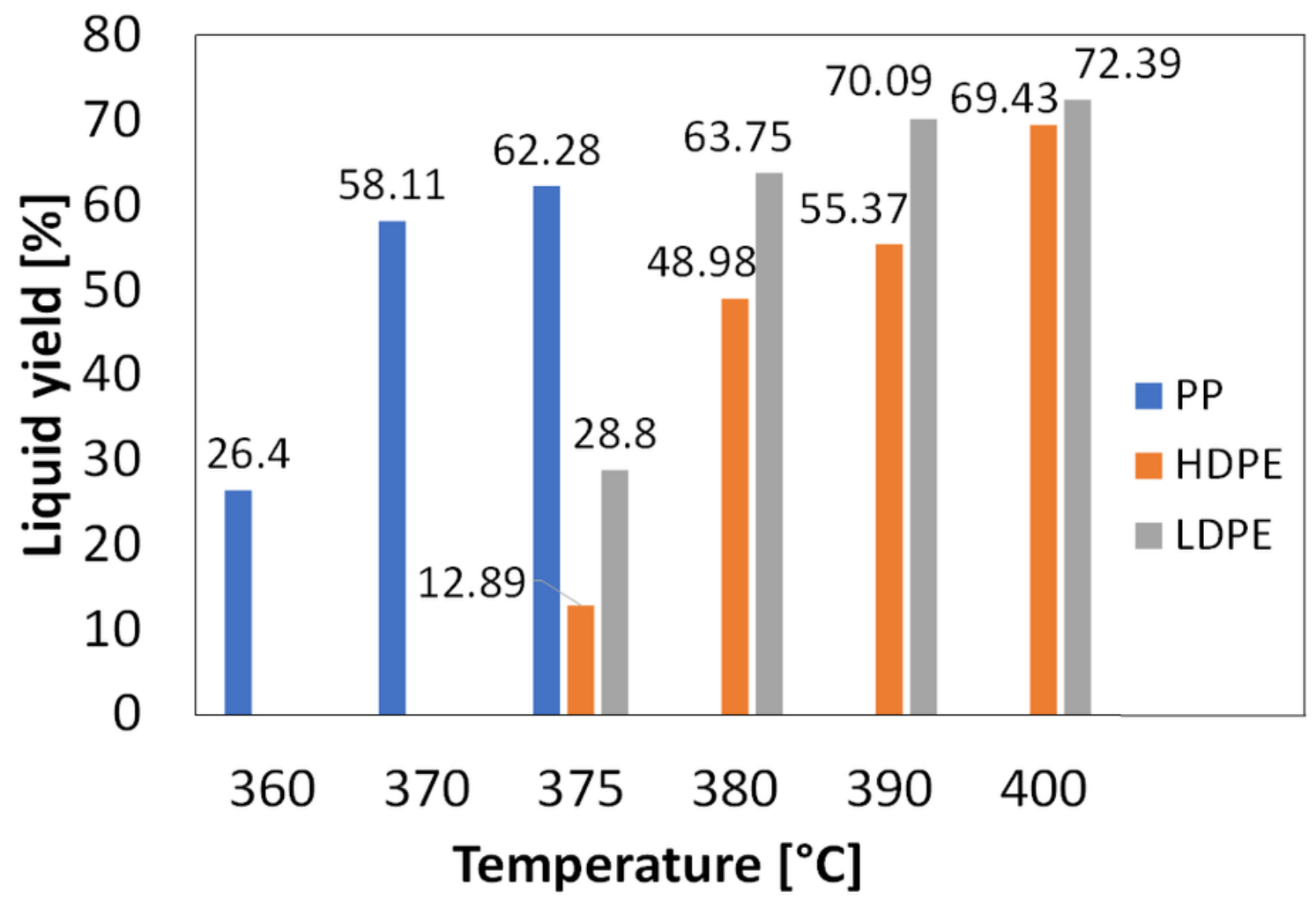

Figure 4

Reaction yield of liquid products for the three plastics as a function of temperature. 

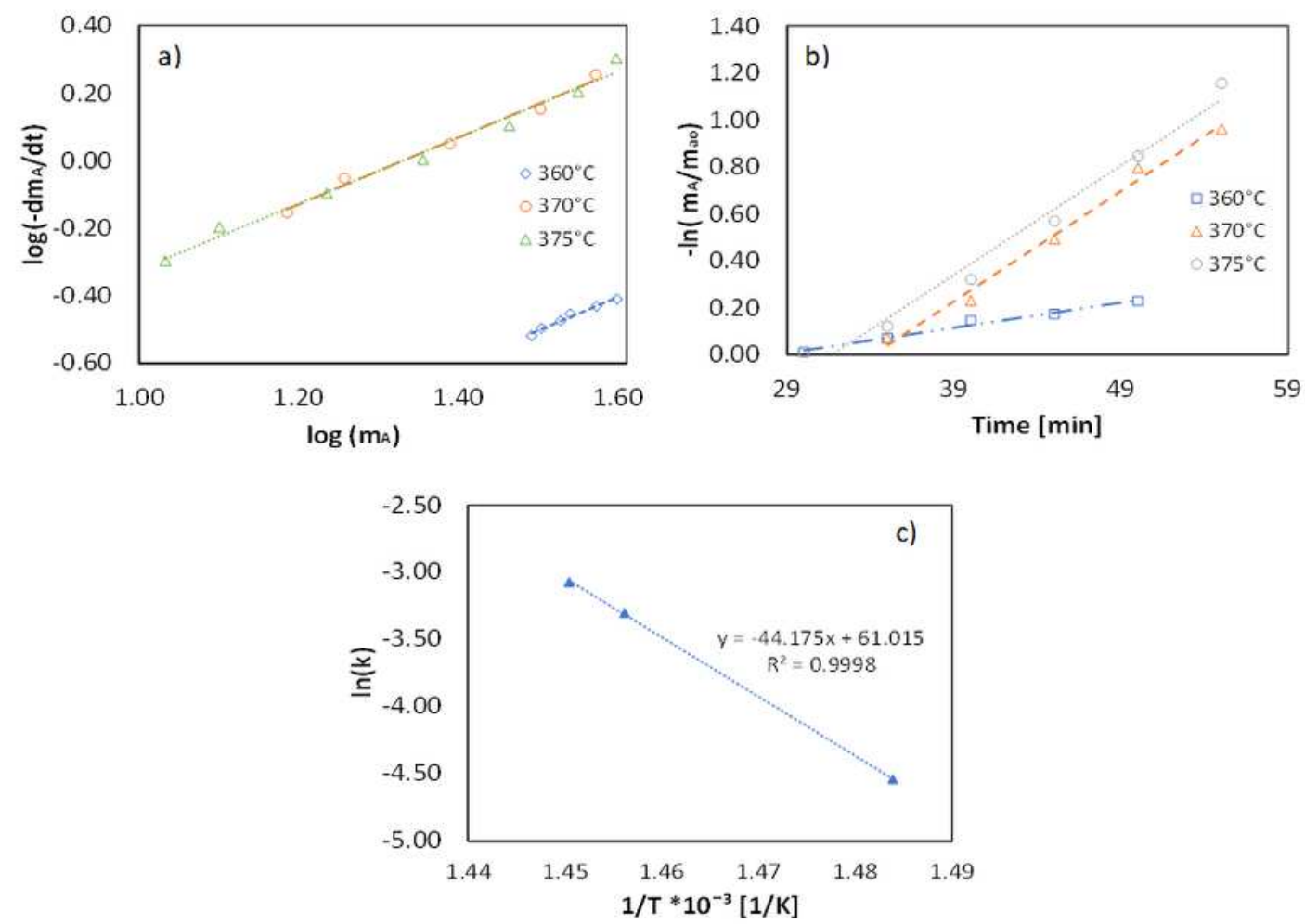

\section{Figure 5}

Graphical methods for the kinetic analysis of the thermal cracking of PP determining: (a) reaction order by differential method, (b) kinetic constant by integral method, and (c) activation energy and preexponential factor by the linearized Arrhenius law 

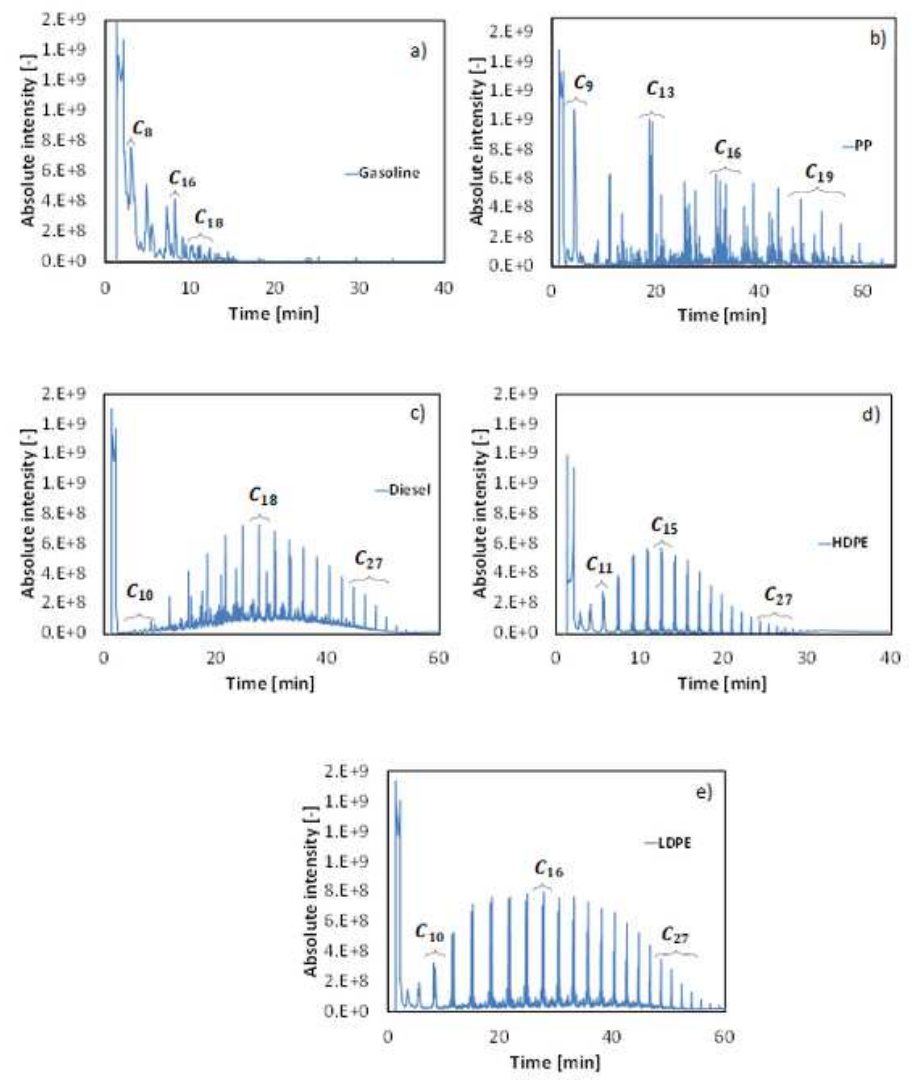

Figure 6

GS-MS chromatograms of (a) gasoline, (b) liquid fractions of PP, (c) diesel, (d) liquid fractions of HDPE, (e) liquid fractions of LDPE.

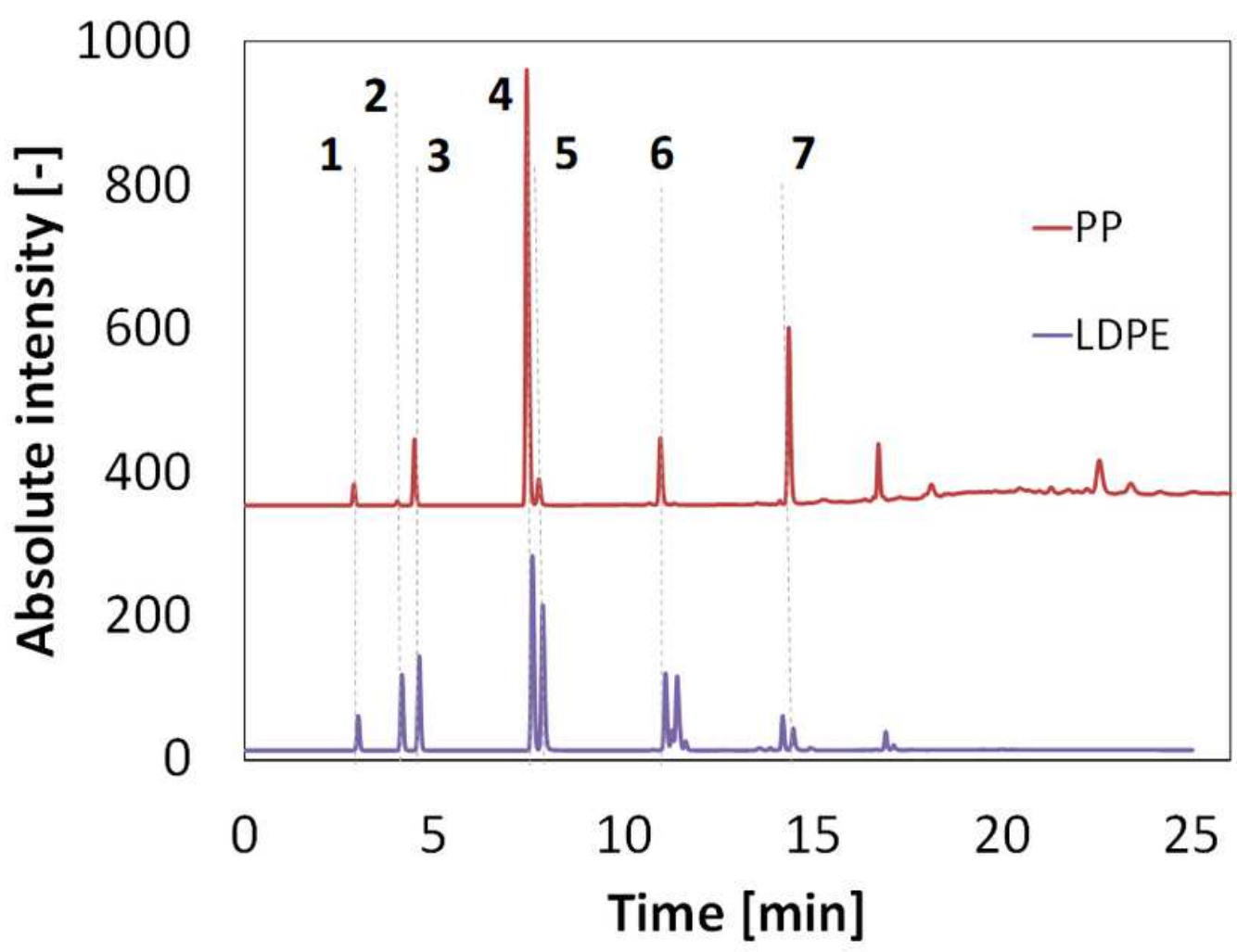


Figure 7

Chromatogram of the gas fractions of PP and LDPE. Peaks: 1 Methane, 2 Ethane, 3 Ethylene, 4 Acetylene, 5 Propane, 6 Propylene, 7 n-Butane.

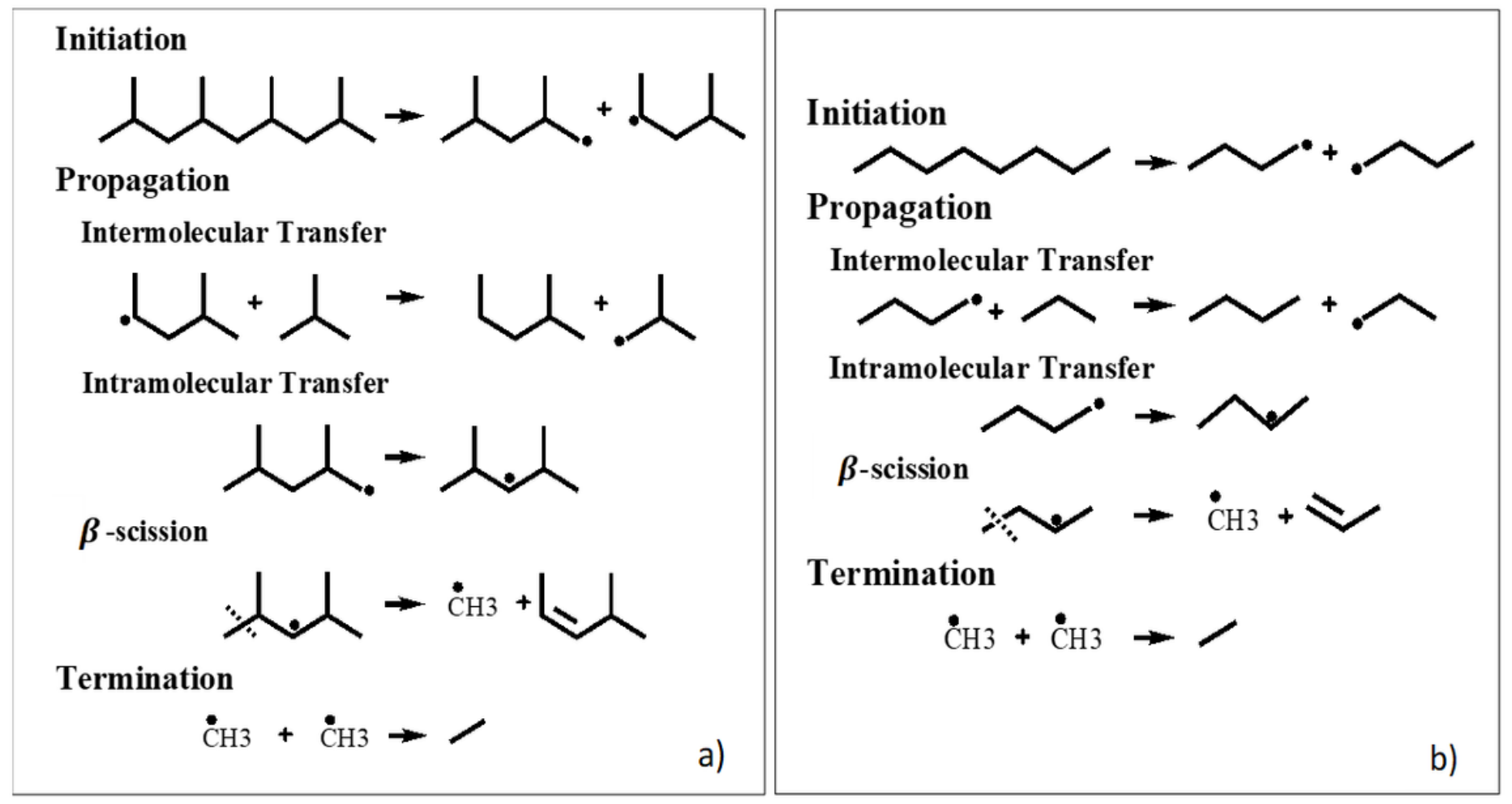

Figure 8

Reaction mechanism of thermal cracking (a) PP and (b) HDPE/LDPE 